\title{
Albert Camus en busca del equilibrio perdido
}

\author{
Monique LANDAIS CHOIMET \\ Universidad Nacional Autónoma de México
}

El objetivo de este artículo consiste en resaltar la actualidad de la obra de Albert Camus en lo que concierne a la búsqueda tenaz y sincera de un equilibrio entre el absurdo de la condición humana y la lucha librada por el hombre para vivir dignamente. Para Camus, la literatura se legitima sólo si trata, con toda conciencia, de los hechos cotidianos de orden social, político o económico, familiar, amoroso o comunitario, sensual, intelectual o espiritual. Así es como se distancia claramente de las corrientes idealistas y naturalistas, surrealistas y existencialistas a fin de llevar a cabo un combate lúcido y pacífico. Hoy muchos literatos franceses retoman este arduo compromiso a favor de un presente loable.

PALABRAS ClaVE: conciencia, compromiso, justicia, sociedad, ética, estética, naturaleza, equilibrio.

The aim of this article is to highlight the relevance of the work of Albert Camus regarding the tenacious and sincere search for a balance between the absurdity of the human condition and the struggle waged by man to live on. For Camus, literature is only legitimate if it is, in all conscience, of daily events, social, political or economic, family, love or community, sensual, intellectual or spiritual order. This is how he stays clearly away from the idealistic and naturalists, surrealist and existentialist currents to carry out a lucid and peaceful struggle. Today many French writers pick up this arduous dedication to a present laudable.

KEY WORDS: conscience, dedication, justice, society, ethics, aesthetics, nature, balance.

La vérité est mystérieuse, fuyante, toujours à conquérir. La liberté est dangereuse, dure à vivre autant qu'exaltante.

A. Camus, Discours: 19

Hablar de Albert Camus para conmemorar el centenario de su nacimiento exige enfocar su vida y su obra desde una perspectiva pluridiscursiva. La literatura, la filosofía, el teatro y el periodismo constituyen, sin lugar a dudas, las cuatro facetas de la obra de este escritor que marcó su época con un sello muy peculiar. Por ende, cualquier lector que pretende analizar, interpretar o criticar la obra camusiana, no puede ignorar su 
multidisciplinariedad. De hecho, el mismo autor veía en la creación de sus novelas y de sus obras de teatro la manera idónea de hablar de filosofía por el solo hecho de que su pensamiento se basaba en imágenes. Así formulaba este principio poético: "Una novela es, en suma, una filosofía puesta en imágenes" (Le Monde: 20). Si pensamos en la más leída de sus novelas, El extranjero, recordamos una imagen que surgió de golpe, que nos deslumbró y nos cegó brutalmente. Al igual que Meursault, el protagonista, nos sentimos agredidos por el destello violento, punzante del sol sobre la hoja del cuchillo que sostiene el árabe. Vivida como una verdadera agresión física, esta simple visión desencadena la tragedia: Meursault dispara una primera vez sobre el árabe y cuatro veces seguidas sobre un cuerpo ya muerto. Esta escena paroxística viene relatada con la mayor sencillez y precisión, dejándonos sin aliento, como para plasmar el movimiento teatral de consecuencia fatal. Definitivamente, Camus logra gravar en la mente de su lector la imagen emblemática del absurdo de la condición humana.

El hecho de recurrir a la imagen como procedimiento literario revela en el autor una firme voluntad de darse a entender por medio de un discurso concreto, cercano a la vida y al mundo, a su propio entorno. Al rechazar la filosofía entendida como discurso abstracto, exposición de ideas y conceptos, se quedaba, de algún modo, fiel a sus modestos orígenes y a sí mismo. Pues, como lo dijera Roger Grenier, uno de sus mejores biógrafos, la filosofía de Camus era una filosofía griega en el sentido de moral: vivir bien y vivir conforme al Bien (Grenier: 9). Esta postura existencial viene claramente ilustrada en su narrativa y en su dramaturgia; basta con citar La peste y Los justos para evocar esta postura profundamente humanista. A este respecto, cabe recordar el homenaje póstumo que Jean-Paul Sartre rindió a Albert Camus, en el cual subraya esta tendencia ética: "Humanisme têtu, étroit et pur, austère et sensuel" (Le Monde: 20). Por lo visto, la literatura y la filosofía existencial vienen aquí íntimamente ligadas ya que "[Camus] n'a jamais séparé sa vie de son aventure de pensée et a toujours joué, donc, le double jeu d'une vie écrite et de livres intensément vécus" (idem.). Así lo enfatiza Bernard-Henri Levy en un artículo publicado en 2010 para conmemorar los cincuenta años del fallecimiento de Camus. Recordamos que el escritor argelino murió en un accidente automovilístico a la edad de cuarenta y siete años, junto con Michel Gallimard, el sobrino de su editor.

Entonces, queda claro que Camus, en tanto que filósofo, no instituyó ningún sistema, ninguna doctrina, sino más bien, ejemplificó una forma de vida, un estilo propio. Y como bien decía Paul Valéry, retomando la célebre máxima de Buffon, "El estilo es el hombre".

Esta reflexión preliminar sobre la especificidad literaria de Camus me llevó a dirigir este artículo hacia dos temáticas que propugnan la trascendencia de sus textos. Me estoy refiriendo a la fraternidad y a la integridad. Para poner en relieve el carácter matricial de la obra de Camus, opté por trazar un paralelo entre tres escritos suyos y tres novelas francesas contemporáneas a fin de observar la huella camusiana vigente todavía. Los autores que voy a mencionar en seguida se pueden considerar como pertenecientes al movimiento nuevo-humanista que contribuye al reencantamiento del 
mundo ${ }^{1}$ asimismo, se pronuncian por esta literatura desconcertante que Nathalie Sarraute definió en los años cincuenta ${ }^{2}$ y después Dominique Viart hacia 1980. Con este calificativo de desconcertante, los críticos aquí referidos querían invitar al lector sagaz a descubrir una expresión literaria provocativa, transgresora tanto a nivel del contenido como del estilo y de la estructura. Al violar las convenciones narrativas, dichas obras causan un patente malestar en el lector llevándolo a una profunda reflexión y autorreflexión. Por lo tanto, bien parece ser que, hoy en día, muchos autores siguen los pasos de Camus, escritor prolífico que concebía la narrativa como un género proteiforme, crítico y regenerador.

\section{Una literatura desconcertante, familiar y asombrosa}

Cuando iniciamos la lectura de El extranjero nos sorprendimos por el estilo turbador del primer párrafo, adoptado como regla por el resto de la novela: "Hoy ha muerto mamá. O quizá ayer. No lo sé. Recibí un telegrama del asilo: 'Falleció su madre. Entierro mañana. Sentidas condolencias'. Pero no quiere decir nada. Quizá haya sido ayer". ${ }^{3}$ Un narrador en primera persona parco, dubitativo, un lenguaje escueto, una sintaxis fragmentada, una serie de enunciados cortos desprovistos de todo nexo, asindéticos. Quisiera subrayar que esta novela fue publicada durante el auge de la Nueva Novela, la cual sin ser ni escuela, ni corriente dada la gran diversidad de las publicaciones que impedían cualquier teorización totalizante, se impuso, a pesar de todo, como una tendencia basada en la sospecha. Nathalie Sarraute intituló su texto teórico La edad del recelo para arremeter en contra de la omnipotencia del autor en la narrativa tradicional, la pretensión del sentido único que hay que develar, el análisis sicológico monolítico que enjuicia y condena, el estilo bello que falsifica y ensueña; en una palabra, Sarraute escribe un manifiesto a favor del renacimiento del género, ya casi caduco. Por lo tanto, entendemos que estamos en una época de transición cuyo objetivo mayor consiste en cuestionar, debatir, erradicar la esclerosis múltiple que ataca tanto al autor como al lector. Frente a esta ruptura epistemológica, surgen dos preguntas esenciales: quién soy y qué hago; qué hago por mí mismo y para el otro.

\footnotetext{
${ }^{1}$ En un ensayo intitulado, Le Désenchantement du monde, Marcel Gauchet insiste en la nueva perspectiva laica (no forzosamente atea) y estética de lo sagrado en los escritos literarios y filosóficos contemporáneos: "Notre capacité d'émotion au spectacle des choses relève d'un mode fondamental d'inscription dans l'être par lequel nous communiquons avec ce qui fut pour des millénaires le sens du sacré. [...] Le sacré, c'est spécifiquement la présence de l'absence, pourrait-on dire, la manifestation sensible et tangible de ce qui normalement est dérobé aux sens et soustrait à l'humaine saisie. Et l'art, au sens spécifique où nous autres modernes le comprenons, c'est la continuation du sacré par d'autres moyens" (Gauchet: 296).

${ }^{2}$ En su ensayo teórico, La era del recelo, Nathalie Sarraute hace un particular énfasis en la obra de Ivy Compton-Burnett, reconocida desde hace poco como una de las mayores novelistas de Inglaterra: "On ne peut qu'admirer le discernement d'une critique et d'un public qui ont su voir la nouveauté et l'importance d'une œuvre déconcertante à bien des égards" (Sarraute: 118).

${ }^{3}$ Web. 17 de septiembre de 2013 <http://www.ciudadseva.com/textos/novela/extran.htm>.
} 
Si consideramos que cada novela queda escrita por completo en el íncipit, entonces veremos reflejada en el uso de esta lengua plana del Extranjero la presencia-ausencia de una madre sorda, casi muda, que fuera origen para Camus de un verdadero trauma. Aquí, conviene precisar que el escritor veneraba literalmente a su madre "diferente, distinta"; la amaba con todo su ser y nos acordamos de la famosísima frase pronunciada antes de que recibiera el Nobel en Estocolmo y que, mal entendida, descontextualizada, provocó tanta polémica: "Aucune cause, même si elle était restée inocente et juste, ne me désolidarisera jamais de ma mère, qui est la plus grande cause que je connaisse au monde" (Le Monde: 8). Camus explicó el sentido de esta afirmación aclarando que, en esta época, los independistas argelinos ponían bombas en los tranvías, por lo que él se comprometía a salvar a su madre en caso de que ella corriera algún peligro, sin ninguna vacilación ni miramiento político.

Pero la pregunta central que se planteaba Camus era la siguiente: cómo lidiar con este silencio materno, esta incapacidad de expresar la emoción, el sentimiento frente a las peores desdichas que acosaban a su familia, entre otras, la enfermedad (la tuberculosis) y la muerte (el fallecimiento del padre en la Primera Guerra Mundial). La comunicación entre madre e hijo era elemental y hasta, a veces, nula por el analfabetismo casi total del entorno familiar. A todo esto hay que agregar que vivían en la pobreza bajo el techo de la abuela, la cual manejaba el látigo con suma destreza. Ya entendemos por qué la muerte de su abuela dejó a Camus impasible.

A pesar de todo, surge de este ambiente familiar un tanto tétrico, un niño dotado para los estudios, un joven comprometido con la palabra y la escritura, y un hombre galardonado con el Premio Nobel de Literatura en 1957. Dadas estas circunstancias, es inevitable preguntarse quién se sentía en realidad extranjero, extraño en este entorno.

\section{Una literatura generosa, socialmente comprometida}

En 1983, es decir cuarenta y un años después de la publicación de El extranjero, Annie Ernaux escribe La Place (El lugar). Los títulos de los dos autores parecen complementarse puesto que invitan al lector, de alguna manera, a buscar y encontrar su propio lugar en una sociedad bastante compleja y, además, adversa. La novela de Annie Ernaux fue catalogada como auto-socio-biografía, etnografía del yo, relato de chamán para exorcismo, autoficción, etcétera; lo cierto es que no dejó indiferentes a los críticos ni a los lectores por las siguientes razones.

Ante todo, comparte con la novela de Camus antes mencionada esta escritura "plate", llana, "blanche", que fue definida por Roland Barthes como el reflejo del desgarramiento de la conciencia burguesa, resultado de la confrontación del escritor con la sociedad (Barthes: 15-16). Si bien es cierto que el origen socioeconómico de Annie Ernaux no es tan pobre como el de Camus, no cabe duda de que constituye el eje rector de su creación poética. Sus padres, que procedían de un medio campesino y obrero, logran comprar a duras penas un pequeño café-comercio en un diminuto municipio de 
Normandía. Ellos viven este ascenso social con mucho orgullo. Sin embargo, el progreso socioeconómico no tiene ninguna influencia en su comportamiento o su modo de hablar (siendo el lenguaje, como bien sabemos, un verdadero estigma social), de tal suerte que su hija se siente "en exilio de sí misma" al volverse profesora de Letras y escritora de novelas premiadas. Ésta es la razón por la cual adopta dicho estilo "neutro" con el fin de atenuar la distancia que resulta de semejante desgarramiento afectivo e intelectual, experimentado por ella como una traición. Esta elección estilística evidencia entonces la función que cumple la literatura para la novelista: escribir le permite prestar su propia voz a los olvidados, a los excluidos de la cultura instituida y de la sociedad en el poder. ${ }^{4}$

Al rechazo de la estetización tradicional de la lengua, hay que agregar la deconstrucción de los personajes que deja atrás el ego clásico definido como unificado, lineal e inteligible para dejar lugar a un sujeto plural, acrónico y enigmático (Gasparini: 163). ${ }^{5}$ Además, Annie Ernaux excluye lo más posible la ficcionalización de la trama para lograr un retrato-testimonio de sus padres y su entorno. De hecho, ella misma dijo que no podía escribir ficción. Por ende, estas normas formales se asemejan a una corriente realista, objetiva, de índole sociológica que pretende dar fe de una realidad singular, sin enjuiciar. Asociada a esta última idea, se perfila una mirada extradiegética, más observadora, distante y reflexiva, que analiza y desestructura, guardándose de narrar según la lógica causal, la cronología lineal o la omnisciencia. Esta narrativa obliga al lector a volverse coautor, en palabras de Umberto Eco, a fin de construir el o los sentidos del texto leído. A este respecto, el semiótico italiano solicitaba "l'activité coopérative qui amène le destinataire à tirer du texte ce que le texte ne dit pas mais qu'il présuppose, promet, implique ou implicite, à remplir les espaces vides, à relier ce qu'il y a dans ce texte au reste de l'intertextualité d'où il naît et où il ira se fondre" (Eco: 5). Hacer de la escritura-lectura una práctica heterónoma en pro de la libertad de expresión constituye una manera muy loable de legitimar la literatura. Entendemos, entonces, que algunos escriben para romper el silencio y conceder algo de justicia a los callados, a los relegados.

\footnotetext{
${ }^{4}$ Resulta interesante constatar este carácter recurrente en varios autores actuales que se pronuncian en contra de la muerte anunciada de la novela. Para explicitar este compromiso a favor del renacimiento de la literatura, el crítico francés Michel Lantelme hace referencia a un síndrome bastante insólito, de origen inesperado. En efecto, el llamado síndrome de Zidane erige el famoso "coup de boule" del futbolista francés originario de La Cabilia, en símbolo de la rabia latente, nacida de la frustración sufrida por alguna injusticia. En este caso, sabemos que la reacción violenta de Zinedine Zidane se debió a un insulto de índole racista, pronunciado por un jugador del equipo adverso italiano (Lantelme: 15).

${ }^{5}$ Philippe Gasparini agrega los ejemplos literarios dados por Serge Doubrovsky para ilustrar estas características ontológicas del ser moderno, hoy ausentes del hombre posmoderno: "Il donnait trois exemples de cette 'sensibilité commune à notre époque post-moderne': L'Amant de Marguerite Duras, Le Miroir qui revient d'Alain Robbe-Grillet et Portrait du joueur de Philippe Sollers"' (Gasparini: 163).
} 


\section{Una literatura ética, subversiva y proselitista}

Por supuesto, este afán de fraternidad rebasa el círculo familiar para abarcar a los grupos sociales desprotegidos. En lo que a Camus concierne, es evidente que siempre se preocupó por ellos, desde sus escritos periodísticos en Argelia. Basta con leer sus reportajes sobre Cabilia realizados en 1939 para percibir una sincera preocupación frente a la penuria y al aislamiento que padecía esta población bajo la tutela francesa:

La Kabylie est un pays surpeuplé et elle consomme plus qu'elle ne produit. [...] le peuple kabyle consomme surtout des céréales, blé, orge, sorgho, sous forme de galette ou de couscous. Or, le sol kabyle ne produit pas de céréales. [...] les Kabyles, comme toutes les nations pauvres et surpeuplées, ont obvié par l'émigration. [...] Mais avec la crise économique, le marché du travail en France s'est restreint. On a mis des barrières à l'émigration et, en 1935, une série d'arrêtés vint compliquer de telle sorte les formalités d'entrée en France que le Kabyle s'est senti de plus en plus enfermé dans sa montagne. [...] C'est cette chute verticale qui a conduit le pays à la misère (Camus, Actuelles: 33-35).

Al leer este texto, nos quedamos impactados por la actualidad de esta crónica: la situación sociopolítica de Cabilia sigue siendo hoy todavía la de muchos países africanos. Y, al igual que Camus, otros autores de principios del siglo XXI manifiestan su firme voluntad de denunciar lo que consideran como una vergüenza para la humanidad. Guiándose por las huellas del autor argelino, Laurent Gaudé recorre, él también, las regiones más desoladas de África en busca de héroes anónimos que dignifican el género humano a expensas de su propia vida.

En 1947, Camus escribe la novela intitulada La peste con el fin de ejemplificar el altruismo protagonizado por el Dr. Rieux que pone su ciencia y su simpatía al servicio de los enfermos; estos últimos bien pueden representar las víctimas de dicha plaga, es cierto, pero también pueden ser los habitantes de cualquier país sometido a un régimen totalitario. La historia relatada en esta novela se desarrolla en la ciudad de Oran, puesta en cuarentena debido a la epidemia. Más que nada, yo veo en esta imagen de la ciudad cercada, aislada, una alegoría del riesgo de ensimismamiento que corre todo ser humano al recluirse en sí mismo. Hasta podemos considerar La peste como una novela epónima en la que el título anuncia al protagonista mayor, la alegoría del Mal, el egoísmo, la indiferencia, la ceguera. Emmanuel Levinas, el filósofo de la ética, considera precisamente este fenómeno de la indiferencia al otro como la peor plaga de nuestra época. Entonces, en este contexto, ejercer su talento de escritor o de médico para ayudar al hermano enfermo, mental o físicamente, responde a la búsqueda de un nuevo Eldorado, resignificado y entendido como mejor mundo desde el punto de vista fraternal y comunitario. ${ }^{6}$

\footnotetext{
${ }^{6}$ En esta resistencia al determinismo consiste la rebeldía entendida por Camus así como sigue: "Dans l'ordre de l'expérience humaine, la révolte a le même sens que le cogito dans l'ordre de la pensée. Elle est
} 
El término mítico, Eldorado, es retomado por Laurent Gaudé para el título de una novela suya publicada en 2006 que trata de la metamorfosis del comandante italiano, Salvatore Piracci, encargado de disuadir a los inmigrantes africanos de entrar al continente europeo por la isla de Lampedusa. Después de cazar durante varios años a estos indocumentados tal y como lo dicta la ley, toma conciencia del carácter criminal de sus actos y opta por borrar todo rastro de su propia identidad antes de emigrar a África. Al igual que los africanos que van en busca de su sueño dorado, su Eldorado europeo, el comandante pierde toda su historia: país, familia, nombre, lengua, costumbres, creencias, amigos, etcétera. La gran diferencia es que él renuncia al primer mundo, a su comodidad y seguridad material, para encontrar un sentido a su vida que le permita trascender los límites de un occidente pragmático y globalizado, engreído y cerrado. En cambio, ellos huyen de la miseria, las guerras, el desempleo, la explotación, y arriesgan todo para conseguir el mismo Eldorado iluso que desprecia Piracci. Frente a semejantes aporías, este último entiende que la dignidad de cada hombre reside en la realización de su sueño y que, por lo tanto, tiene que ayudar a los emigrantes a cumplirlo. En El mito de Sísifo, escrito en 1942, Albert Camus exigía la rebelión constante en contra del absurdo, la libertad lúcida frente al destino y la pasión inagotable para restablecer la justicia:

Je laisse Sysiphe au bas de la montagne! On retrouve toujours son fardeau. Mais Sysiphe enseigne la fidélité supérieure qui nie les dieux et soulève les rochers. Lui aussi juge que tout est bien. Cet univers désormais sans maître ne lui paraît ni stérile ni futile. Chacun des grains de cette pierre, chaque éclat minéral de cette montagne pleine de nuit, à lui seul forme un monde. La lutte elle-même vers les sommets suffit à remplir un cœur d'homme. Il faut imaginer Sysiphe heureux (Camus, Le mythe: 168).

Desde este ángulo, cualquier obstáculo se percibe como un reto cuyo objetivo consiste en recobrar la imagen de un hombre, digno y libre, rebelde. Si nos remitimos una vez más a Levinas, recordamos que el hecho de encontrarse cara a cara con el otro responde para el filósofo a una exigencia ética a-tea, es decir anterior a cualquier religión; por consiguiente, este último término teológico pierde su dimensión vertical, trascendental, para designar una relación horizontal, fraternal, de solidaridad. En este mismo orden de ideas, la mirada sincera, lúcida y consciente, preconizada por Emmanuel Levinas, acerca a los hombres más allá de toda diferencia e indiferencia. No olvidemos que el propio Camus participó en la Resistencia durante la Segunda Guerra Mundial, de manera muy discreta pero, a la vez, tan notoria que sus actos heroicos para salvar a muchos judíos perseguidos por el nazismo le valieron la Medalla de la Cruz de Guerra. Entonces, entendemos que la literatura es una manifestación subversiva, estética y ética, que deja mucho para pensar y actuar.

la première vérité et elle est la première valeur" (Camus, Essais: 1687). Claro está que el lector asiduo de la obra camusiana se percata del interés permanente del autor por los temas de actualidad, sean de índole política, social o económica, haciendo así de sus escritos unas críticas agudas a la sociedad injusta y narcisista. 


\section{Una literatura estética, empática y solar}

Este breve retrato comparativo de Camus a través de su obra y de su influencia perceptible en la expresión literaria contemporánea quedaría truncado, y hasta erróneo, de no tomar en cuenta un tercer elemento, el cual aparece, después de la familia y de la sociedad, como un actante ayudante ${ }^{7}$ de importancia mayor: me estoy refiriendo a la naturaleza. De hecho, el sol, el mar, el viento y el calor, son constitutivos tanto del hombre que fue Camus como del escritor. Escuchémoslo hablar del mar, de su poder estructurante y dignificante:

¡Gran mar siempre trabajado, siempre virgen, mi religión con la noche! El mar nos lava y nos colma en sus estériles surcos. Nos libera y nos mantiene erguidos. A cada ola nos hace una promesa, siempre la misma. ¿Qué dice la ola? Si tuviera que morir, rodeado de frías montañas, ignorado del mundo, renegado por los míos, en fin, al cabo de mis fuerzas, el mar vendría a último momento a llenar mi celda, vendría a sostenerme por encima de mí mismo y a ayudarme a morir sin odio. ${ }^{8}$

Otro Premio Nobel de Literatura, Jean-Marie Gustave Le Clézio, les concede hoy en día la misma importancia vital a estos elementos naturales ya que le procuran una felicidad plena que él llama "éxtasis material". Asimismo, le otorga un valor ontológico a esta experiencia simbiótica dado que permite al hombre recuperar la armonía con la naturaleza, muchas veces perdida u olvidada. Esta simbiosis resulta ser una fuente primordial de equilibrio e integridad.

Dentro de la misma temática, Camus publica en 1939 Bodas, una recopilación de ensayos dentro de los cuales uno lleva por título "El Desierto". Ahí le agradece a su maestro, Jean Grenier, el haberle enseñado la lección del Mediterráneo, cálido y generoso. Por el lirismo del relato y las sinestesias tan sugestivas, compartimos la vivencia con la naturaleza a manera de catarsis. La pureza natural que lo envuelve decuplica sus fuerzas a la vez que lo sumerge en una belleza fascinante. Dichas experiencias culminantes entrañan ocasionalmente una lucidez tal que el hombre toma conciencia de una paradoja implacable: la conducta hedonista que lo lleva a disfrutar del mundo, olvidando por un tiempo su carácter absurdo y trágico, refuerza la necesidad de la rebeldía ética para combatir precisamente lo absurdo y lo trágico. Acaso, ¿esta exigencia propia no se asemeja a una ascesis que apunta a recuperar la integridad mental y física, moral y social, espiritual e intelectual? Por su parte, Albert Camus agradecía este don de la naturaleza de modo efusivo $y$, a la vez, lúcido: “je fus placé à mi-distance de la misère et du soleil. La misère m'empêcha de croire que tout est bien sous le soleil et dans

\footnotetext{
${ }^{7}$ Web. 15 de mayo de 2014 <file://C:/Users/S\%C3\%A9bastien/Downloads/Dialnet-LinguisticaYNarrativa-144029.pdf-24>. Nos referimos aquí a la terminología de Greimas.

${ }^{8}$ Web. 20 de septiembre de $2013<$ http://lejosdeltiempo.wordpress.com/2013/05/08/albert-camus>.
} 
l'histoire ; le soleil m'apprit que l'histoire n'est pas tout. Changer la vie, oui, mais non le monde dont je faisais ma divinité" (Camus, 1958b: 30).

Curiosamente, aparece en 1980 una novela de Le Clézio intitulada Desierto; su estructura dual confronta dos existencias distanciadas por el tiempo pero tristemente unidas por la Historia con "H" mayúscula. En efecto, al principio del siglo XX una tribu de nómadas cruza el desierto del Sahara y se dirige hacia la costa mediterránea en busca de mejores condiciones de vida. Al final del siglo XX, Lalla, una hermosa joven descendiente de esta misma tribu, quiere probar su suerte en el continente europeo. Los primeros serán aniquilados por los soldados franceses mientras que la segunda se verá transformada en cover girl por un fotógrafo francés ávido de lucro. Lalla regresa a su país donde la esperan el mar, el sol y el viento; aquí es donde reencontramos la sensualidad camusiana:

[Lalla] pense au vent, qui est grand, transparent, qui bondit sans cesse au-dessus de la mer, qui franchit en un instant le désert, jusqu'aux forêts de cèdres, et qui danse là-bas, au pied des montagnes, au milieu des oiseaux et des fleurs. Le vent n'attend pas. Il franchit les montagnes, il balaie les poussières, le sable, les cendres, il culbute les cartons, il arrive quelquefois jusqu'à la ville de planches et de carton goudronné et il s'amuse à arracher quelques toits et quelques murs. Mais ça ne fait rien, Lalla pense qu'il est beau, transparent comme l'eau, rapide comme la foudre, et si fort qu'il pourrait détruire toutes les villes du monde s'il le voulait, même celles où les maisons sont hautes et blanches avec de grandes fenêtres de verre (Le Clézio: 80).

Esta descripción alegórica se vuelve háptica al transformar el viento en algo tangible, palpable y bien parece ser que comunica su vigor a la muchacha que lo acoge en su ser, cuerpo y mente. Soplo de vida, cual llamarada. Y para cerciorarnos de la vigencia de esta actitud esperanzadora mejor meditemos sobre esta última máxima: "J'ai découvert qu'un enfant pauvre pouvait s'exprimer et se délivrer par l'art" (Camus, C.: 28). Sin que subsista la menor duda, el arte permite al hombre herido recobrar el equilibrio perdido por el odio, el rencor o la cólera. A través de esta ventana ética y estética, la mirada aguda de Camus se tiñe de benevolencia, la palabra incisiva se torna pacifista, el tono conminatorio se vuelve atento y la intención apunta a la convivencia armoniosa, respetuosa y a la escucha ajena. El escritor argelino admiraba mucho a Gandhi pero decía que no alcanzaba tal grandeza. Sin embargo, bien parece ser que los dos pensadores siguen avivando hoy en día la búsqueda de una mayor justicia para todos y cada uno de nosotros.

\section{Obras citadas}

BARTHES, Roland. [1953]. Le degré zéro de l'écriture. París: Seuil, 1972. Impreso. Camus, Albert. Essais. París: Gallimard / La Pléiade, 1965. Impreso. Discours de Suède. París: Gallimard / NRF, 1958a. Impreso. 
. Actuelles III. París: Gallimard, 1958b. Impreso. La peste. París: Gallimard / Folio, 1947. Impreso. Le mythe de Sysiphe. París: Gallimard / Folio Essais, 1942. Impreso.

Camus, Catherine. Albert Camus. Solitaire et solidaire. Neuilly-sur-Seine: Éditions Michel Lafon, 2009. Impreso.

Eco, Umberto. Lector in fabula. París: Grasset, 1979. Impreso.

ERnaUX, Annie. La place. París: Gallimard / Folio, 1983. Impreso.

Gasparini, Philippe. Autofiction. Une aventure du langage. París: Seuil, 2008. Impreso.

GAUChET, Marcel. Le désenchantement du monde. París: Gallimard, 1985. Impreso. GAUDÉ, Laurent. Eldorado. París: Actes Sud, 2006. Impreso.

GrenIER, Roger. Albert Camus soleil et ombre. París: Gallimard, 1987. Impreso.

Lantelme, Michel. Le roman contemporain. Janus postmoderne. París: L'Harmattan, 2008. Impreso.

Le ClÉzIO, Jean-Marie Gustave. Désert. París: Gallimard / Folio, 1980. Impreso.

Le Monde, Hors-Série. "Albert Camus. La révolte et la liberté”. M08392. 2010. Impreso.

SARRAUTE, Nathalie. L'ère du soupçon. París: Gallimard, 1956. Impreso.

Web. 15 de mayo de $2014<$ file:///C:/Users/S\%C3\%A9bastien/Downloads/DialnetLinguisticaYNarrativa-144029.pdf- 24>.

Web. 20 de septiembre de $2013<$ http://lejosdeltiempo.wordpress.com/2013/05/08/ albert-camus>.

Web. 17 de septiembre de $2013<$ http://www.ciudadseva.com/textos/novela/extran. htm>. 